\section{LA EVOLUCIÓN \\ DE LA METALURGIA PREHISTÓRICA EN LA PROVINCIA DE ALICANTE (1)}

\author{
PREHISTORIC COPPER METALLURGY \\ DEVELOPMENT IN ALICANTE \\ PROVINCE (SPAIN)
}

\section{ALFREDO GONZÁLEZ PRATS (*)}

\section{RESUMEN}

El trabajo intenta presentar una visión actualizada de la evolución de la metalurgia prehistórica del cobre en tierras alicantinas desde mediados del III milenio hasta los inicios de la Edad del Hierro, incidiendo en la existencia de una metalurgia ya desde momentos pre-campaniformes. En el Bronce Antiguo la tipología metálica cambia, aún con útiles fabricados de cobre arsenicado. Desde 1600 a.C. comienzan a aparecer objetos de bronce binario, generalizándose en el Bronce Final.

\begin{abstract}
This paper endeavours to present an actualized view of prehistoric copper metallurgy development in Alicante Province from the middle of the third millennium to the early Iron Age, insisting on the appearance of the metallurgy even in pre-beaker times. Typology changes in the Early Bronze Age, showing implements still made in arsenical bronze. Binary bronzes appear during the Middle Bronze Age, becoming widespread during the Late Bronze Age.
\end{abstract}

(*) Área de Prehistoria. Departamento de Prehistoria, Arqueología, Historia Antigua, Filología Griega y Filología Latina. Universidad de Alicante. Apartado de Correos 99. E 03080 Alicante. Tel.: (96) 5903400 Ext. 3002.

El artículo fue remitido en su versión final el 22-XII-95.
Palabras clave: Metalurgia. Tecnología metalúrgica. Aleaciones. Calcolítico. Campaniforme. Edad del Bronce. Bronce Final.

Key words: Metallurgy. Metallurgical technology. Alloys. Chalcolithic. Beaker. Bronze Age. Late Bronze Age.

\section{INTRODUCCIÓN}

El conocimiento de las actividades metalúrgicas en la provincia de Alicante (Fig. 1) viene estrechamente condicionado, en primer lugar, por la escasez de mineralizaciones de cobre -fenómeno extensible al resto del País Valenciano--, considerándose como un área secundaria en la génesis de la metalurgia. Y, en segundo lugar, por la propia naturaleza de los datos.

La información de que disponemos para el tramo cronológico a través del cual se desarro-

(1) El texto recoge fielmente el contenido de la conferencia pronunciada el día 28 de septiembre de 1995 en el Curso "El despertar de la metalurgia en el Sudeste peninsular", celebrado en Lorca en el marco de los cursos de la Universidad del Mar de la Universidad de Murcia. 


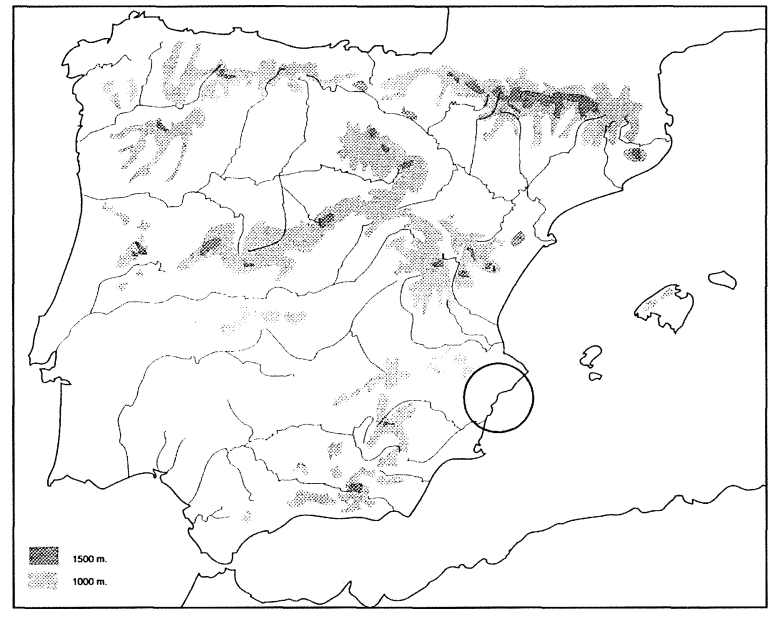

Fig. 1. Situación de la provincia de Alicante en la Península Ibérica.

lla la metalurgia prehistórica y protohistórica de base cobre -entre 2400 y 650 a.C.- es bastante desigual, en ocasiones incompleta y a menudo carente de contexto. Como ocurre en otras áreas, la dedicación de las investigaciones en poblados prehistóricos principalmente del II milenio a.C., ha posibilitado un mayor volumen de datos no sólo sobre los objetos manufacturados, sino también sobre las actividades estrictamente tecnológicas (escorias, crisoles, martillos, etc.).

En líneas generales, podríamos subrayar la cualidad y la cantidad de los elementos de análisis en tres áreas principales: en primer lugar, en las Sierras de Orihuela-Callosa-Crevillente; en segundo lugar, en el corredor del Vinalopó $y$, por último, en la montaña alcoyana. Esto es así merced básicamente a los trabajos de Furgús, Moreno y Colominas en el Bajo Segura, de varios investigadores en el Vinalopó (Hernández Pérez, 1982, 1983, 1985, 1986, 1989 y 1994; Navarro Mederos, 1982,) así como a los meritorios trabajos de J.M. Soler García (1981) en la comarca de Villena y de la pléyade de investigadores aglutinados en torno al Museo de Alcoy (Ponsell, 1926; Botella, 1926; Visedo, 1959 , etc.), incluyendo los trabajos de quien esto suscribe en los yacimientos pre y protohistóricos de la Sierra de Crevillente (González Prats, 1986, 1989c, 1990a, 1992a y 1993b; González Prats y Ruiz Gálvez, 1989).

\section{LA METALURGIA DEL III MILENIO a.C.}

El marco conceptual en el que se inscriben las interpretaciones sobre el origen y evolución de las actividades metalúrgicas en la zona objeto del trabajo no es otro que el mismo que afecta al resto del territorio peninsular: la cuestión de la génesis de la metalurgia hispana como un proceso autóctono o como una tecnología adquirida por el contacto con otras sociedades que la conocían, todo ello en un momento más o menos avanzado de la Edad del Cobre.

El trabajo más reciente sobre el particular, referido al Sudeste peninsular, se decanta por considerar más adecuada a la realidad la hipótesis de un desarrollo local de la metalurgia, contemplando los tres fenómenos siguientes: la ausencia de contactos con culturas metalúrgicas alóctonas, el primitivismo tecnológico peninsular en relación con otros focos y el continuismo cultural (Montero Ruiz, 1992: 204; y 1994: 272).

En la actualidad, la información disponible apunta hacia la existencia de una metalurgia precampaniforme más o menos generalizada por toda la Península Ibérica (Almagro Gorbea, 1978; Delibes et alii, 1988 y 1989; Arribas et alii, 1989; Dos Santos Gonçalves, 1989; Montero Ruiz, 1992).

Para el País Valenciano, la cuestión de una actividad metalúrgica en época precampaniforme ha sido ampliamente debatida, encontrándonos con autores que han apoyado decididamente su existencia (Aparicio et alii, 1981; Lerma, 1981; Soler García, 1981; Corral Cañón, 1986) al lado de otros que niegan su entidad con anterioridad al Horizonte Campaniforme de Transición (HCT) (Bernabeu Auban, 1984 y 1986; Bernabeu Aubán et alii, 1987) (Fig. 2).

Uno de los últimos trabajos de conjunto sobre la metalurgia en el País Valenciano es la tesis doctoral de J.L. Simón García, defendida en junio de 1995 en la Universidad de Alicante. El autor desmitifica enconadamente la metalurgia precampaniforme haciendo uso de argumentos dispares. Uno de ellos es la cronología campaniforme del poblado de Les Moreres (González Prats y Ruiz Segura, 1994), en su día catalogado como precampaniforme (González 


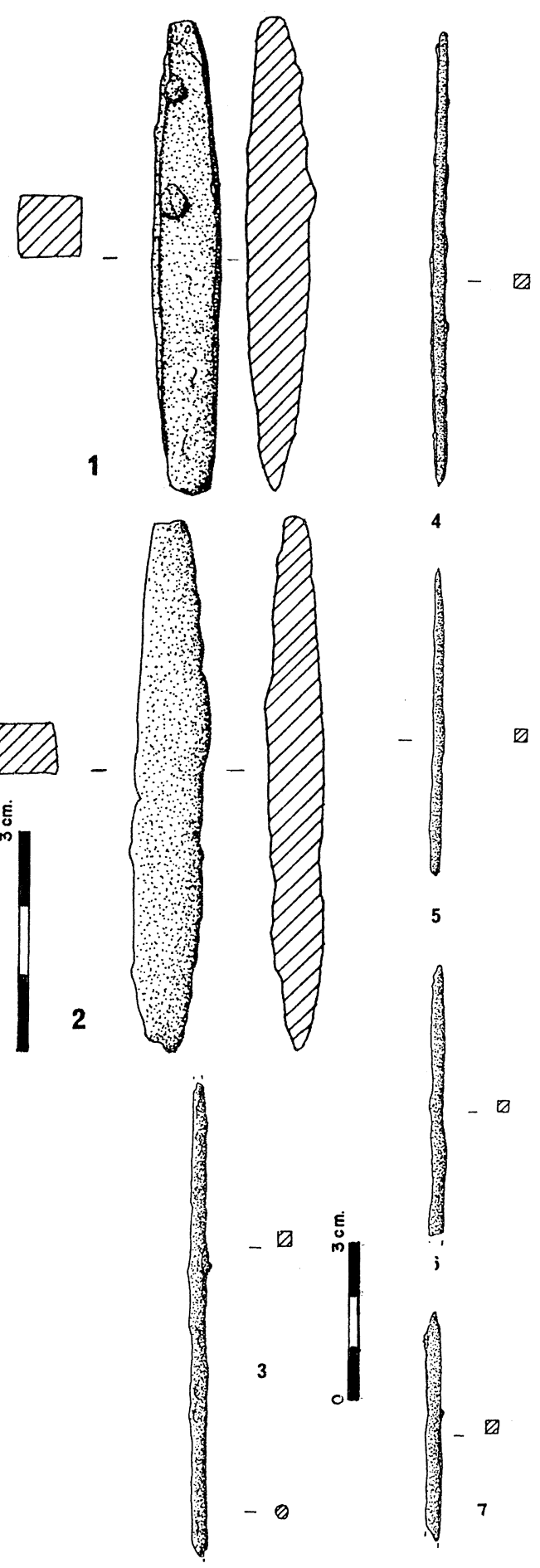

Fig. 2. Objetos de metal de la etapa precampaniforme: escoplos y punzones de la Cova de la Barcella en Torremanzanas, Alicante (Borrego et alii, 1992).
Prats, 1986c) ante la ausencia de esta especie decorada en los primeros registros.

Al hilo de este hecho hemos de puntualizar dos cuestiones. Por un lado, el estrecho marco cronológico que concede el citado autor al desarrollo del campaniforme, acorde con la datación tradicional del HCT, a caballo entre el III y II milenios a.C. (Fig. 3). Diversos trabajos sobre esta problemática (Harrison, 1988; Martín Valls y Delibes, 1989) aconsejan considerar un espacio temporal más amplio que cubriría toda la segunda mitad del III milenio y las dos primeras centurias del II. En esa línea, las fases con cerámica campaniforme de Les Moreres deben hallar su lugar cronológico en el último tercio del III milenio, acorde con lo que indica el resto del contexto material, propio de un enclave del tipo Millares-Malagón.

Por otro, seguimos desconociendo detalles de la fase más antigua del poblado calcolítico. En el registro de las fases campaniformes, en efecto, ha aparecido un pequeño puñal de lengüeta, toda vez que en superficie se han recuperado dos puntas Palmela. Pero el conjunto mayor de objetos metálicos viene definido por punzones biapuntados de sección cuadrada y un pequeño escoplo, cuya producción no tiene por qué vincularse necesariamente a aquellos objetos asociados tradicionalmente al fenómeno campaniforme.

Otro argumento esgrimido incide en la validación de la tesis tendente a considerar las alabardas o cuchillos bifaciales de sílex que hallamos en varios enclaves calcolíticos del Sudeste y Levante meridional como imitaciones de los puñales metálicos (Courtin, 1974; Cabanilles, 1990), con lo que su cronología sería necesariamente tardía: "De este conjunto, el único elemento distorsionador es el punzón de cobre, que posee todas las características de estos instrumentos en las fases más antiguas, es decir, su gran longitud, extremos biapuntados y una sección y grosor similares a lo largo de toda su longitud. En nuestra opinión, se trata de un punzón de momentos precampaniformes, perteneciente a uno de los últimos enterramientos efectuados en la necrópolis" (Simón García, 1995: 846, inédito).

De este modo, Simón García, a pesar de reconocer que el punzón de La Algorfa pertene- 

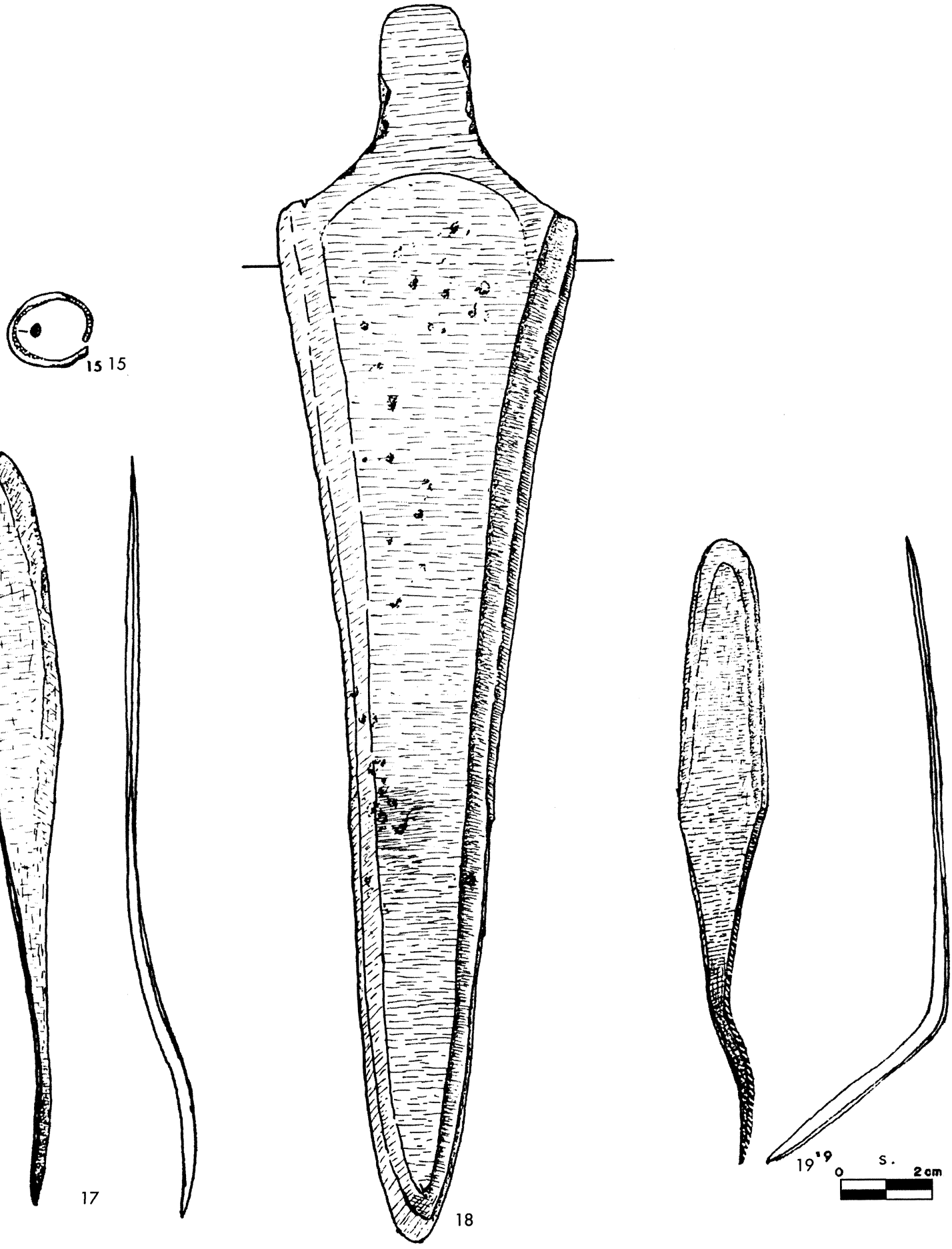

Fig. 3. Objetos de metal de la fase campaniforme tardía: puñal de lengüeta, puntas Palmela y arete de plata de la Cueva oriental del Peñón de la Zorra de Villena, Alicante (Soler, 1981).

T. P., 53, n. ${ }^{\circ} 1,1996$ 
ce a la etapa precampaniforme, no tiene inconveniente alguno para -apoyándose en la existencia de uno de estos puñales de sílex en dicha necrópolis y dando por sentada su cronología avanzada- asumir que se trata, en última instancia, de un objeto de prestigio: "Coetáneamente a las primeras cerámicas campaniformes, las cuales todavía no se habían incorporado a estos grupos humanos culturalmente calcolíticos en momentos cronológicos campaniformes" (Simón García, 1995: 847, inédito).

Con tales argumentos, muchos de los punzones primitivos hallados en contextos de cuevas de enterramiento colectivo han sido trasladados a época campaniforme -en cronología corta tradicional-, asignándoseles incluso una funcionalidad - harto cuestionable - como sustitutos de las agujas de hueso para el tocado del cabello.

Los análisis realizados sobre las piezas metálicas de Les Moreres han deparado un conjunto homogéneo de cobres arsenicales (Tabla 1).

Estos valores nos emplazan ante la problemática de si estos contenidos en arsénico son fruto del polimetalismo de los minerales originarios, considerándose así un componente no separado, o si, en cambio, se trata de un elemento aleado intencionadamente, tal y como han venido defendiendo algunos investigadores (Charles, 1967; Harrison y Craddock, 1981; Hook et alii, 1987; Delibes et alii, 1988; Arribas et alii, 1989). Estos valores entran en los parámetros de la composición de los objetos de cobre de los yacimientos tipo Millares, con concentraciones de arsénico entre 1 y $3 \%$ (Arribas et alii, 1989: 77).

Como colofón a la cuestión del origen de la metalurgia del cobre en el III milenio a.C. en la fachada sudeste de la Península Ibérica, permítasenos llamar la atención sobre la presencia de cerámicas monocromas rojas de origen anatólico en Les Moreres (González Prats et alii, 1995), por cuanto su difusión por la cuenca mediterránea ha sido relacionada con el inicio de las actividades metalúrgicas (Mellink, 1993), con lo que podríamos manejar una posible argumentación para explicar la aparición de la metalurgia en la Península Ibérica de modo paralelo a la recepción de estas

\begin{tabular}{|l|c|c|c|c|}
\hline Muestra & $\mathrm{Cu}$ & $\mathrm{As}$ & $\mathrm{Sn}$ & $\mathrm{Pb}$ \\
\hline Moreres 1 & 98,65 & 1,34 & $\mathrm{n}$ & $\mathrm{n}$ \\
\hline Moreres 3 & 97,88 & 1,49 & $\mathrm{n}$ & $\mathrm{n}$ \\
\hline Moreres 4 & 97,60 & 2,39 & $\mathrm{n}$ & $\mathrm{n}$ \\
\hline Moreres 5 & 98,26 & 1,74 & $\mathrm{n}$ & $\mathrm{n}$ \\
\hline Moreres 6 & 97,30 & 2,70 & $\mathrm{n}$ & $\mathrm{n}$ \\
\hline Moreres 7 & 97,55 & 2,45 & $\mathrm{n}$ & $\mathrm{n}$ \\
\hline Moreres 9 & 98,50 & 1,50 & $\mathrm{n}$ & $\mathrm{n}$ \\
\hline Moreres 10 & 98,36 & 1,64 & $\mathrm{n}$ & $\mathrm{n}$ \\
\hline Moreres 981 & 98,03 & 1,82 & $\mathrm{n}$ & $\mathrm{n}$ \\
\hline
\end{tabular}

Tabla 1. Análisis metálicos de objetos del poblado de Les Moreres, Crevillente, Alicante (Calcolítico).

cerámicas importadas, en una línea no desechada por algunos investigadores (Delibes $e t$ alii, 1988).

\section{LA EDAD DEL BRONCE}

Para la Edad del Bronce, disponemos de un mayor volumen de información propiciado, como decíamos, por la existencia de un más amplio registro arqueológico a través de excavaciones en yacimientos tan paradigmáticos como San Antón, Laderas del Castillo, Caramoro I, Tabayá, La Horna, Isleta del Campello, Cabezo Redondo, Mas de Menente, Ull del Moro, Mola Alta de Serelles o Peña Negra (Fig. 4).

En el apartado de las actividades mineras y metalúrgicas, ahora contamos con una buena representación de crisoles, moldes de arenisca, mazas, morteros con cazoletas y escorias, que nos ilustra sobre la generalización de las actividades metalúrgicas en la provincia alicantina, al compás de lo que sucede en el resto del territorio peninsular.

La primitiva tipología a base de punzones, escoplos y anillos, ampliada con los tipos que se asocian al campaniforme, ve acrecentado el número de objetos a partir del Bronce Antiguo. Numerosos útiles y armas hacen su aparición por primera vez en Alicante, como es el caso de las hachas planas, inexistentes en épocas precedentes en la zona, junto con los tipos clásicos del II milenio a.C. 


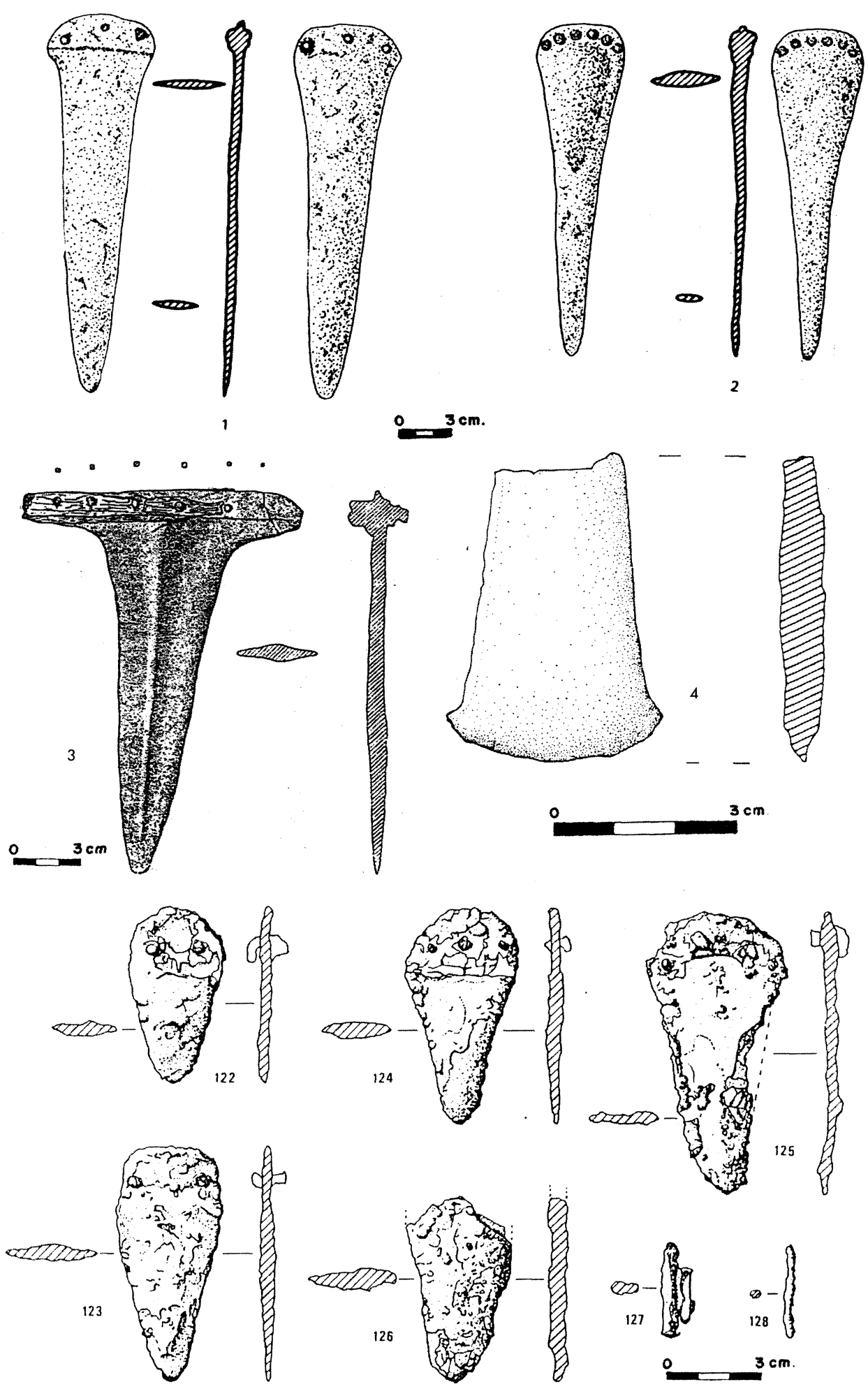

Fig. 4. Objetos de metal de la Edad del Bronce: cuchillos (1 y 2), alabarda (3), hacha plana (4) y pequeños cuchillos (122-128), procedentes de la Isleta de Campello, Tabayá y San Antón de Orihuela, Alicante (Simón, 1988; Hernández, 1983 y 1989; Diz, 1982).

T. P., 53, n. ${ }^{\circ} 1,1996$ 
Pero no creo que podamos establecer una relación de paridad incluso entre aquellos yacimientos mejor conocidos citados, ya que ofrecen una notoria disimetría en la cualidad del registro al tratarse en unos casos de poblados y en otros de poblados asociados a necrópolis, como sería el caso de los enclaves pertenecientes al ámbito argárico (San Antón, Laderas del Castillo, Tabayá, Isleta de Campello), cuyas sepulturas han deparado importantes ajuares metálicos, difíciles de igualar en los registros estratigráficos de los poblados. La adscripción cultural de estos yacimientos al Argar o al Bronce Valenciano actúa, por tanto, de factor distorsionador en el registro material.

Este fenómeno se aprecia ante una mayor representación de tipos en el área argárica de la provincia de Alicante, en donde el número de puñales de remaches, hachas y alabardas resulta significativo en relación con el resto del territorio, más desvinculado de la influencia del Sudeste. Alabardas y objetos de marfil constituirían elementos de prestigio que escasean o se enrarecen hacia el Norte, a la par que no se ha constatado claramente ninguna espada y los adornos de oro y plata se polarizan en dos zonas: Orihuela, un núcleo argárico de primer orden que B. Blance (1971) equiparó al propio de El Argar, y Villena, un área de transición que denota su predilección por dicha orfebrería desde el Bronce Antiguo.

Precisamente, el desconocimiento de la facies funeraria en la mayoría de los poblados alicantinos de la Edad del Bronce impide llevar a efecto con éxito reconstrucciones socio económicas en base al equipamiento metálico, a pesar de lo cual se puede caer en la tentación de teorizar sobre el grado de jerarquización social, jefatura y capitalidad territorial en contados núcleos. Esta vía interpretativa no sólo necesita del concurso de bienes relevantes dotados de significación social y prestigio - objetos metálicos, marfil, orfebrería- sino más bien de una información precisa sobre el grado y el modo de la explotación, control y dominio del territorio, en consonancia con las tendencias actuales que tienden a minimizar el papel desempeñado por el metal como elemento de diferenciación social (Chapman, 1991; Gilman, 1976 y 1987; Montero, 1992).
En el campo puramente tecnológico, desde que en 1959 Beatrice Blance realizara los primeros análisis de objetos metálicos, la tesis del empleo de un cobre arsenical durante el II milenio a.C. tomó carta de naturaleza en la investigación de las dos décadas siguientes. Con el tiempo, la iniciativa de un sistemático análisis arqueometalúrgico como paso previo para el conocimiento de la tecnología metalúrgica, llevó a algunos autores a señalar la existencia en este período de verdaderos objetos de bronce binario (Hernández Pérez, 1983; Martí Oliver, 1983).

Una reciente propuesta (Simón García, 1995: 888, inédito), en consonancia con lo señalado por otros autores en el Sudeste (Arribas et alii, 1989: 78), pretende ubicar exclusivamente en el Bronce Tardío todos los objetos metálicos que contienen estaño. Pero un análisis del texto de I. Montero (1992: 196) — que sirve de plataforma para esta pretensión-: "Aleaciones intencionadas no se consiguen hasta época argárica con el uso de los bronces..., aunque por desgracia no se puede por el momento determinar con precisión el inicio de estas prácticas. Si atendemos a los datos disponibles en otras regiones peninsulares para el caso del bronce, quizá no pueda situarse su aparición mucho antes de la mitad del II milenio a.C." y una revisión de los listados de los análisis que acompañan a dicho trabajo, nos emplazan ante la presencia de objetos de bronce binario en el Bronce Pleno, corroborando los asertos de los propios Siret (1890: 227) y de Lull (1983: 439). En sentido igualmente contrario apuntan los resultados analíticos de objetos metálicos de yacimientos de la Meseta, en donde existen bronces binarios desde el Bronce Pleno (Rovira y Montero, 1994).

Los resultados de los análisis de los objetos metálicos de la fortificación argárica de Caramoro I en el Bajo Vinalopó, insistirían en la misma tendencia (Tabla 2).

La argumentación de que la composición de las piezas metálicas procedentes del foco argárico de Orihuela-Callosa, al carecer de estaño - a excepción de un único ejemplar-, demostraría que el bronce binario no era conocido durante el Bronce Antiguo y Pleno en uno de los focos metalúrgicos más dinámi- 


\begin{tabular}{|l|l|l|l|l|}
\hline Muestra & $\mathrm{Cu}$ & $\mathrm{As}$ & $\mathrm{Sn}$ & $\mathrm{Pb}$ \\
\hline Car I.588 & 98,17 & 1,49 & $\mathrm{n}$ & $\mathrm{n}$ \\
\hline Car I.589 & 95,12 & $\mathrm{n}$ & 4,77 & $\mathrm{n}$ \\
\hline Car I.590 & 97,24 & 2,74 & $\mathrm{n}$ & $\mathrm{n}$ \\
\hline Car I.591 & 97,03 & 2,89 & $\mathrm{n}$ & $\mathrm{n}$ \\
\hline
\end{tabular}

Tabla 2. Análisis metálicos de piezas del poblado de Caramoro I, Elche, Alicante (Bronce pleno).

cos y por tanto la aleación con estaño debió producirse más tarde, no parece consistente. En primer lugar, tanto en San Antón como en Las Laderas existen materiales demostrativos de una perduración o, al menos, ocupación durante el Bronce Tardío (cerámicas excisas e incisas). En segundo lugar, la industria metalúrgica local de esta zona se abastecía de metalotectos carentes de estaño, lo que no significa tanto que en época argárica no se conociera el bronce binario como que en la zona de Orihuela-Callosa no se utilizaba al abastecerse de materia prima local y por tanto no necesitar importar objetos metálicos de otras zonas productoras del Sudeste. Otra de estas importaciones de bronce binario, sí llegó - como se puede apreciar en el escoplo núm. 589- a Caramoro I, posiblemente acompañando al grupo de cerámicas importadas procedentes de la región murciano-almeriense, es decir, a un yacimiento cuya cronología no baja más allá del 1600-1500 a.C.

Uno de los puntales, pues, de la tesis de Simón García corre el peligro de convertirse en un apriorismo no contrastado. La convicción del autor en la ecuación Cobre + Estaño $=$ Bronce Tardío en el País Valenciano, lo conduce a defender la utilización hasta esa época del rito del enterramiento colectivo en cuevas y covachos, como propugna para la Cueva del Cantal de Biar, la Casa Colorá de Elda o la Cueva de las Delicias de Villena. Resulta, a todas luces, menos forzado admitir la posibilidad de la adscripción de los objetos de bronce hallados en estos lugares, que sobresalen de los otros objetos de cobre arsenical, a un momento del Bronce Antiguo o Pleno y considerarlos objetos importados, constriñendo unas tradiciones funerarias del neolítico II-Calcolítico que pare- cen estar totalmente caducadas a mediados del II milenio a.C.

No creo, permítaseme insistir, que el contenido en estaño del puñal de remaches del Mas de Felip en Ibi deba utilizarse para situar en este momento tardío de la Edad del Bronce la necrópolis de inhumación. Según los datos que manejé en su día (González Prats, 1973), la asociación de una hermosa alabarda, que con posterioridad se pretendió disociar de su contexto (Cerdá Bordera, 1983: 81), puede arrojar luz en sentido contrario. La tipología de la alabarda, cuya forma ha causado extrañeza a algún investigador, puede asimilarse, sin dificultad, a una variante del tipo "Carrapatas", característica del Bronce Antiguo de la fachada atlántica peninsular (Schubart, 1973; Ruiz Gálvez, 1979), con lo que dispondríamos de un élemento cronológico que acortaría el período de uso de la necrópolis colectiva del Mas de Felip.

Ello no obsta para que, a tenor de los análisis arqueometalúrgicos, debamos admitir que en el último tercio del II milenio, es decir, en el Bronce Tardío a.C, se produzca el hecho de la generalización de la metalurgia del auténtico bronce en el País Valenciano y en el Sudeste, seguramente obedeciendo a una reorientación de las relaciones culturales y comerciales con el mundo atlántico a través de las gentes de Cogotas I. Sin embargo, no es menos cierto que los objetos de cobre arsenical van a seguir manteniéndose hasta el final del ciclo de la metalurgia del cobre, ya que, como ha sido apuntado por varios autores, el fenómeno es ilustrativo de las "distribuciones irregulares y aleatorias debido a las características particulares del mineral empleado y a las condiciones de trabajo fuera del control del metalúrgico" (Montero Ruiz, 1992: 196).

Yacimientos adscritos a esta fase avanzada de la Edad del Bronce, como el Cabezo Redondo, La Horna, La Pedrera, La Peña de Sax o El Tabayá, ofrecen objetos metálicos de bronce. Habremos de esperar, no obstante, a la publicación del trabajo doctoral de Simón García para apreciar la proporción de bronces con respecto a los cobres, si se ha realizado un amplio muestreo (Tablas 3 y 4 ).

T. P., 53, n. ${ }^{\circ} 1,1996$ 


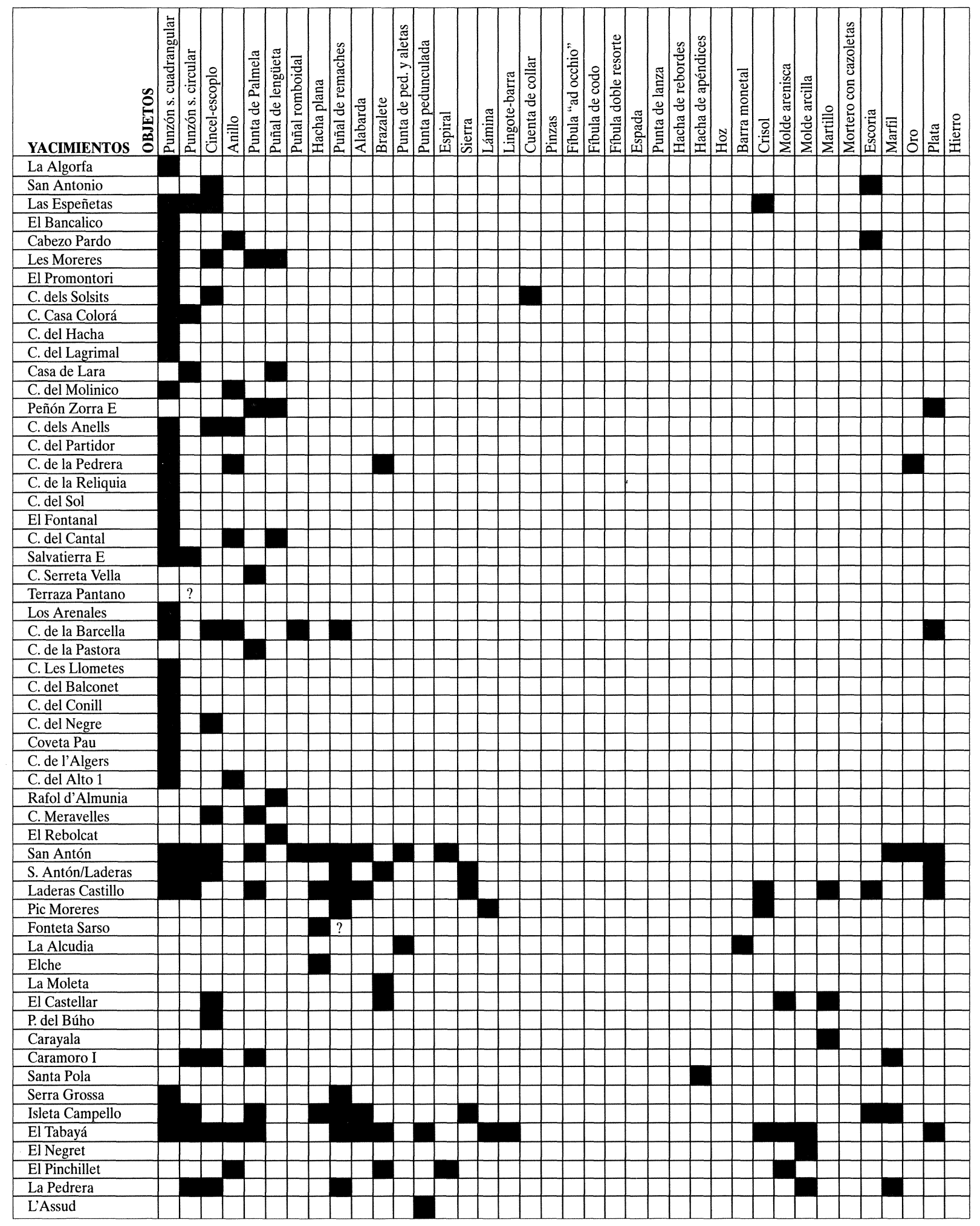

Tabla 3. Objetos metálicos y evidencias de laboreo metalúrgico en los yacimientos prehistóricos y protohistóricos alicantinos. 


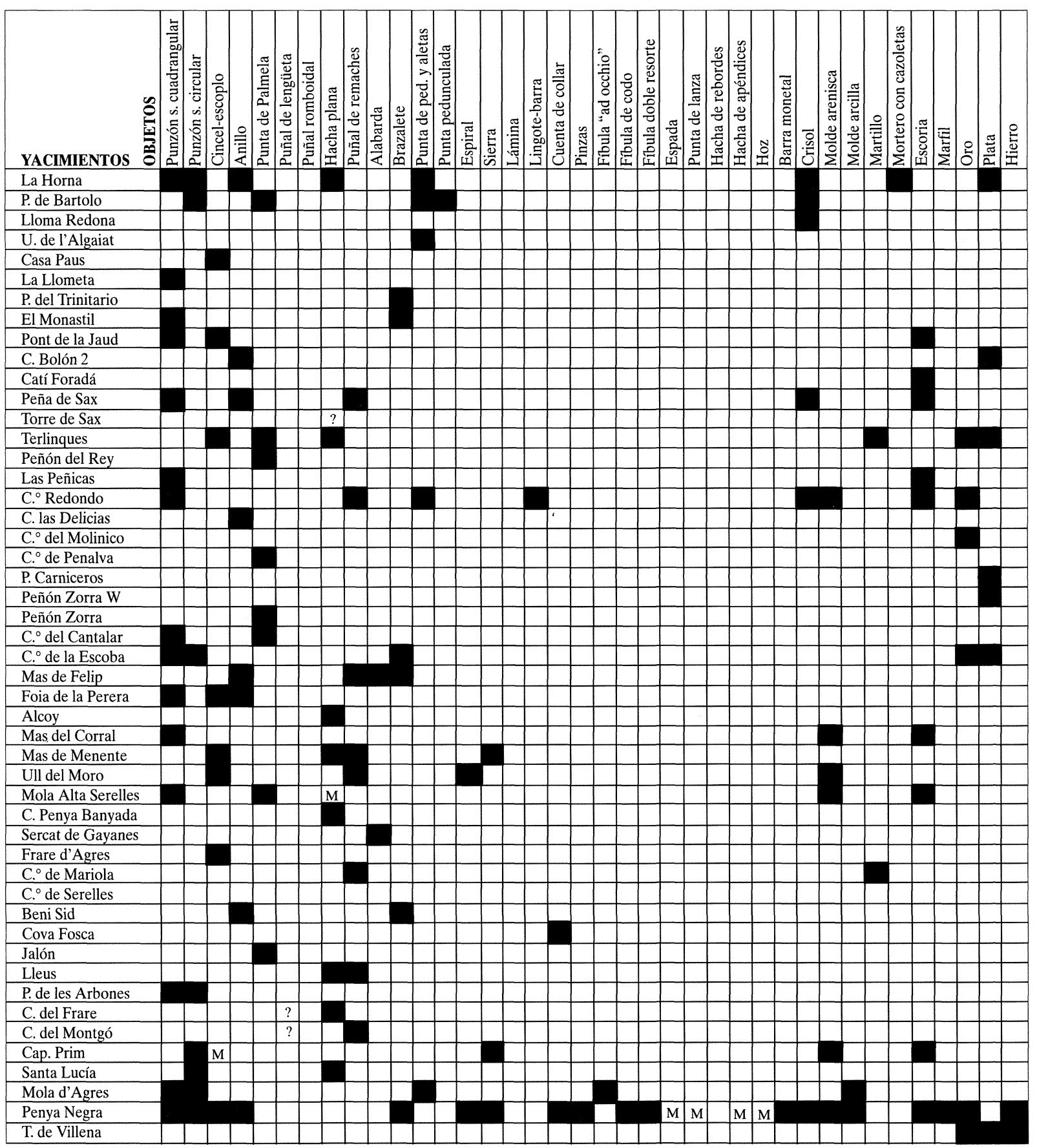

Tabla 4. Objetos metálicos y evidencias de laboreo metalúrgico en los yacimientos prehistóricos y protohistóricos alicantinos. 


\section{LA NUEVA TECNOLOGÍA DEL BRONCE FINAL}

El tránsito del II al I milenio a.C. viene definido por el Bronce Final. Esta fase terminal de la Edad del Bronce inaugura, con propiedad, un período en donde vamos a observar importantes novedades en los campos cultural, funerario y tecnológico.

En cuanto a las actividades metalúrgicas, a pesar del escaso número de yacimientos conocidos y excavados, disponemos de una información de primer orden traducida en el hallazgo de un impresionante taller de fundición en el gran poblado de La Peña Negra, un excelente exponente de las nuevas tecnologías que se imponen en el Bronce Final III, entre los siglos IX y VIII a.C., en estas tierras del Sudeste (González Prats, 1989, 1990a, 1992a y 1993a; González Prats y Ruiz Gálvez, 1989).

La disponibilidad, además, de una información contrastada entre las actividades realizadas en el poblado, los objetos recuperados en sus registros estratigráficos y aquéllos procedentes de las tumbas de cremación de la necrópolis correspondiente, nos sitúa en condiciones óptimas de manejar datos de suma fiabilidad, cuya representatividad puede aplicarse a todo el Sudeste y el Levante meridional en esta época.

La tradicional tecnología de elaboración de piezas mediante moldes bivalvos de piedra que podíamos observar en varios poblados del II milenio a.C., cede su lugar ante una nueva técnica basada en el empleo mayoritario de los moldes de arcilla - algunos moldes de arenisca siguen utilizándose-, que se generaliza contemporáneamente en el Occidente europeo, como demostrarían los hallazgos de Fort-Harrouard (Mohen, 1973, 1984, 1984-85 y 1985; Mohen y Bailloud, 1987), Soto de Medinilla en Valladolid (Delibes, 1985: 93) o del castro de El Royo en Soria (Eiroa, 1981), con una cronología paralela al taller de fundidor de Peña Negra.

Los más de 400 fragmentos de moldes de arcilla del yacimiento de la Sierra de Crevillente sitúan en pleno Sudeste una febril actividad metalúrgica cuyo indudable aire atlántico confiere un destacado papel a esta región como hito en la progresión de dicha metalurgia por el Mediterráneo (Ruiz Gálvez, 1986).

Un elevado número de objetos característicos del Bronce Final III se elaboraban en los talleres de Crevillente: espadas, puntas de lanza, hachas de apéndices laterales, hoces, agujas y brazaletes, entre otros muchos objetos no identificables por el grado de fragmentación de los moldes. La producción del poblado no tiene representación en la necrópolis, en donde únicamente hallamos pequeños adornos metálicos (anillas, brazaletes, cuentas de collar). Como tampoco ha sido hallada en el poblado siquiera una mínima representación de las piezas fabricadas, da la impresión de que se trata de una producción destinada al abastecimiento de una demanda exterior, de proyección mediterránea.

Si contemplamos los útiles metálicos "hispánicos" hallados en el depósito de Sa Idda, en Cerdeña (Taramelli, 1921), junto a la presencia de fíbulas de codo de tipo sículo en el Sudeste (Mola d'Agres, Peña Negra, Cerro de los Infantes, Cerro de la Miel, Cerro Alcalá y Cerro de la Mora) que se distribuyen hacia el interior, como dan fe los ejemplares de Perales del Río, San Román de la Hornija (Delibes, 1978) o del castro burgalés de Yecla en Silos (González Salas, 1945), entre otros, dispondremos de claras evidencias de este movimiento comercial entre la fachada oriental de la Península Ibérica y el Mediterráneo central en época precolonial, al que posiblemente debamos atribuir la presencia de tipos metálicos tan genuinamente "mediterráneos" como las hachas de apéndices laterales (Coffyn, 1985; Molina, 1978) fabricadas tanto en Peña Negra como en Verdolay (Ros Sala, 1980).

Los análisis realizados sobre escorias y objetos del poblado y sobre ajuares de la necrópolis ofrecen un panorama diversificado de aleaciones, en donde se emplean los componentes de acuerdo con las necesidades (González Prats y Ruiz Gálvez, 1989; González Prats, 1993d): cobres prácticamente puros, cobres arsenicales, bronces binarios y ternarios conviven y se elaboran conjuntamente en virtud del distinto destino o funcionalidad de las piezas metálicas. Así, el bronce binario se reserva, entre otras, para aquellas piezas que requieren un elevado grado de dureza y tenacidad —espadas, puntas

$$
\text { T. P., 53, n. }{ }^{\circ} 1,1996
$$


de lanza, hachas - mientras el cobre o bronce plomado constituye la base de la fabricación de objetos que no requieren, en principio, tales propiedades, como es el caso de los adornos. Sin embargo, podemos observar en los análisis que presentamos a continuación, cómo el bronce binario se utiliza perfectamente para la confección de objetos suntuarios (Tabla 5).

Ofrecemos en este trabajo, un avance de los resultados de la analítica arqueometalúrgica aplicada a un muestreo de los ajuares de la necrópolis del Bronce Final de Peña Negra, ubicada sobre el nivel calcolítico de Les Moreres. La ausencia de arsénico en casi todas las piezas, nos emplazaría ante la cuestión de nuevo de su representación como elemento añadido inten-

\begin{tabular}{|c|c|c|c|c|c|c|c|}
\hline Muestra & $\mathrm{Cu}$ & Sn & $\mathrm{Pb}$ & As & $\mathrm{Ni}$ & $\mathrm{Fe}$ & $\mathrm{Au}$ \\
\hline S.1 & 90,37 & 9,63 & $n$ & $\mathrm{n}$ & $n$ & $\mathrm{n}$ & $\mathrm{n}$ \\
\hline S.2 & 90,90 & 9,10 & $n$ & $n$ & $\mathrm{n}$ & $n$ & $n$ \\
\hline S.3 & 94,35 & 5,65 & $\mathrm{n}$ & $\mathrm{n}$ & $\mathrm{n}$ & $\mathrm{n}$ & $\mathrm{n}$ \\
\hline S.4 & 95,79 & 4,21 & $\mathrm{n}$ & $\mathrm{n}$ & $\mathrm{n}$ & $\mathrm{n}$ & $\mathrm{n}$ \\
\hline S.5 & 93,78 & 6,22 & $\mathrm{n}$ & $\mathrm{n}$ & $\mathrm{n}$ & $\mathrm{n}$ & $\mathrm{n}$ \\
\hline S.6 & 90,55 & 8,01 & 0,86 & $n$ & $n$ & 0,57 & $\mathrm{n}$ \\
\hline S.7 & 88,50 & 7,74 & 3,74 & $n$ & $\mathrm{n}$ & $\mathrm{n}$ & $\mathrm{n}$ \\
\hline S. 8 & 89,14 & 10,86 & $\mathrm{n}$ & $\mathrm{n}$ & $\mathrm{n}$ & $\mathrm{n}$ & $\mathrm{n}$ \\
\hline S.9 & 96,11 & 3,89 & $\mathrm{n}$ & $\mathrm{n}$ & $\mathrm{n}$ & $\mathrm{n}$ & $\mathrm{n}$ \\
\hline S.10 & 91,77 & 8,23 & $\mathrm{n}$ & $\mathrm{n}$ & $\mathrm{n}$ & $\mathrm{n}$ & $\mathrm{n}$ \\
\hline S.11 & 85,30 & 14,70 & $n$ & $\mathrm{n}$ & $\mathrm{n}$ & $\mathrm{n}$ & $\mathrm{n}$ \\
\hline S.12 & 48,75 & 50,06 & $\mathrm{n}$ & $\mathrm{n}$ & 0,75 & $\mathrm{n}$ & $n$ \\
\hline S.13 & 88,43 & 7,37 & 4,20 & $\mathrm{n}$ & $\mathrm{n}$ & $\mathrm{n}$ & $n$ \\
\hline S.14 & 93,91 & 5,49 & $\mathrm{n}$ & $\mathrm{n}$ & $\mathrm{n}$ & 0,60 & $n$ \\
\hline S.15 & 67,24 & 28,66 & $\mathrm{n}$ & $\mathrm{n}$ & $\mathrm{n}$ & $\mathrm{n}$ & $\mathrm{n}$ \\
\hline S.16 & 87,47 & 12,53 & $\mathrm{n}$ & $\mathrm{n}$ & $\mathrm{n}$ & $\mathrm{n}$ & $\mathrm{n}$ \\
\hline S.18 & 88,33 & 11,67 & $\mathrm{n}$ & $\mathrm{n}$ & $\mathrm{n}$ & $\mathrm{n}$ & $\mathrm{n}$ \\
\hline S.19 & 93,66 & 6,34 & $\mathrm{n}$ & $\mathrm{n}$ & $\mathrm{n}$ & $\mathrm{n}$ & $\mathrm{n}$ \\
\hline S.20 & 93,79 & 6,21 & $n$ & $\mathrm{n}$ & $\mathrm{n}$ & $\mathrm{n}$ & $\mathrm{n}$ \\
\hline S.21 & 88,26 & 11,74 & $n$ & $n$ & $\mathrm{n}$ & $n$ & $n$ \\
\hline S.22 & 88,35 & 11,65 & $n$ & $n$ & $\mathrm{n}$ & $\mathrm{n}$ & $\mathrm{n}$ \\
\hline S.23 & 94,04 & 5,91 & $\mathrm{n}$ & $\mathrm{n}$ & $\mathrm{n}$ & $\mathrm{n}$ & $\mathrm{n}$ \\
\hline S.24 & 86,17 & 13,83 & $\mathrm{n}$ & $\mathrm{n}$ & $\mathrm{n}$ & $\mathrm{n}$ & $\mathrm{n}$ \\
\hline S.25 & 78,42 & 21,58 & $\mathrm{n}$ & $\mathrm{n}$ & $\mathrm{n}$ & $\mathrm{n}$ & $\mathrm{n}$ \\
\hline S.26 & 91,85 & 8,15 & $\mathrm{n}$ & $n$ & $\mathrm{n}$ & $\mathrm{n}$ & $\mathrm{n}$ \\
\hline S.27 & 93,30 & 6,70 & $n$ & $n$ & $\mathrm{n}$ & $\mathrm{n}$ & $\mathrm{n}$ \\
\hline S.28 & 81,13 & 18,87 & $\mathrm{n}$ & $\mathrm{n}$ & $\mathrm{n}$ & $\mathrm{n}$ & $\mathrm{n}$ \\
\hline S.29 & 94,60 & 5,40 & $\mathrm{n}$ & $n$ & $\mathrm{n}$ & $\mathrm{n}$ & $\mathrm{n}$ \\
\hline S.30 & 86,64 & 13,36 & $\mathrm{n}$ & $\mathrm{n}$ & $\mathrm{n}$ & $\mathrm{n}$ & $\mathrm{n}$ \\
\hline S.31 & 90,84 & 6,31 & 2,85 & $\mathrm{n}$ & $\mathrm{n}$ & $\mathrm{n}$ & $\mathrm{n}$ \\
\hline S. 32 & 90,50 & 9,50 & $n$ & $\mathrm{n}$ & $\mathrm{n}$ & $\mathrm{n}$ & $n$ \\
\hline S.33 & 78,45 & 21,55 & $\mathrm{n}$ & $n$ & $\mathrm{n}$ & $\mathrm{n}$ & $\mathrm{n}$ \\
\hline 1.5 & 84,48 & 15,52 & $\mathrm{n}$ & $\mathrm{n}$ & $\mathrm{n}$ & $\mathrm{n}$ & $\mathrm{n}$ \\
\hline
\end{tabular}

T. P., 53, n. ${ }^{\circ} 1,1996$

\begin{tabular}{|c|c|c|c|c|c|c|c|}
\hline Muestra & $\mathrm{Cu}$ & $\mathrm{Sn}$ & $\mathrm{Pb}$ & As & $\mathrm{Ni}$ & $\mathrm{Fe}$ & $\mathrm{Au}$ \\
\hline 4.5 & 99,66 & 0,34 & $n$ & $\mathrm{n}$ & $n$ & $n$ & $n$ \\
\hline 4.6 & 89,39 & 10,61 & $\mathrm{n}$ & $\mathrm{n}$ & $\mathrm{n}$ & $\mathrm{n}$ & $\mathrm{n}$ \\
\hline 10 & 99,50 & $\mathrm{n}$ & $n$ & 0,25 & $\mathrm{n}$ & 0,25 & $n$ \\
\hline 31.2 & 90,25 & 9,75 & $n$ & $\mathrm{n}$ & $\mathrm{n}$ & $\mathrm{n}$ & $\mathrm{n}$ \\
\hline 32.1 & 92,40 & 7,60 & $\mathrm{n}$ & $\mathrm{n}$ & $\mathrm{n}$ & $\mathrm{n}$ & $\mathrm{n}$ \\
\hline 32.2 & 88,16 & 5,03 & 6,81 & $\mathrm{n}$ & $\mathrm{n}$ & $\mathrm{n}$ & $\mathrm{n}$ \\
\hline 36.4 & 96,66 & 6,34 & $\mathrm{n}$ & $\mathrm{n}$ & $\mathrm{n}$ & $\mathrm{n}$ & $\mathrm{n}$ \\
\hline 42.2 & 91,91 & 8,09 & $\mathrm{n}$ & $\mathrm{n}$ & $\mathrm{n}$ & $\mathrm{n}$ & $\mathrm{n}$ \\
\hline 48.3 & 89,87 & 9,39 & $\mathrm{n}$ & $\mathrm{n}$ & $\mathrm{n}$ & 0,70 & $\mathrm{n}$ \\
\hline 51.3 & 91,34 & 8,66 & $\mathrm{n}$ & $\mathrm{n}$ & $\mathrm{n}$ & $\mathrm{n}$ & $\mathrm{n}$ \\
\hline 51.4 & 91,49 & 8,51 & $\mathrm{n}$ & $\mathrm{n}$ & $\mathrm{n}$ & $\mathrm{n}$ & $\mathrm{n}$ \\
\hline 56 & 78,74 & 8,13 & 12,84 & $\mathrm{n}$ & $\mathrm{n}$ & $\mathrm{n}$ & $\mathrm{n}$ \\
\hline 63.2 & 88,27 & 11,73 & $\mathrm{n}$ & $\mathrm{n}$ & $\mathrm{n}$ & $\mathrm{n}$ & $\mathrm{n}$ \\
\hline 63.3 & 91,16 & 7,38 & 1,46 & $\mathrm{n}$ & $\mathrm{n}$ & $\mathrm{n}$ & $\mathrm{n}$ \\
\hline 65.4 & 66,98 & 33,02 & $\mathrm{n}$ & $\mathrm{n}$ & $\mathrm{n}$ & $\mathrm{n}$ & $n$ \\
\hline 66.2 & 79,83 & 20,17 & $\mathrm{n}$ & $\mathrm{n}$ & $\mathrm{n}$ & $\mathrm{n}$ & $\mathrm{n}$ \\
\hline 67.3 & 73,75 & 15,97 & 10,26 & $\mathrm{n}$ & $\mathrm{n}$ & $\mathrm{n}$ & $\mathrm{n}$ \\
\hline 67.4 & 91,52 & 8,48 & $\mathrm{n}$ & $\mathrm{n}$ & $\mathrm{n}$ & $\mathrm{n}$ & $\mathrm{n}$ \\
\hline 67.5 & 85,97 & 14,03 & $\mathrm{n}$ & $\mathrm{n}$ & $\mathrm{n}$ & $\mathrm{n}$ & $n$ \\
\hline 67.6 & 90,88 & 9,12 & $\mathrm{n}$ & $\mathrm{n}$ & $\mathrm{n}$ & $\mathrm{n}$ & $n$ \\
\hline 73.5 & 85,44 & 14,56 & $\mathrm{n}$ & $\mathrm{n}$ & $\mathrm{n}$ & $\mathrm{n}$ & $\mathrm{n}$ \\
\hline 75.2 & 95,71 & 4,29 & $n$ & $\mathrm{n}$ & $\mathrm{n}$ & $\mathrm{n}$ & $\mathrm{n}$ \\
\hline 78.2 & 87,90 & 12,10 & $\mathrm{n}$ & $\mathrm{n}$ & $\mathrm{n}$ & $\mathrm{n}$ & $\mathrm{n}$ \\
\hline 87 & 88,46 & 6,61 & 4,92 & $\mathrm{n}$ & $\mathrm{n}$ & $\mathrm{n}$ & $\mathrm{n}$ \\
\hline 90.3 & 92,87 & 6,54 & 0,58 & $\mathrm{n}$ & $\mathrm{n}$ & $\mathrm{n}$ & $\mathrm{n}$ \\
\hline 90.4 & 88,86 & 11,14 & $\mathrm{n}$ & $\mathrm{n}$ & $\mathrm{n}$ & $\mathrm{n}$ & $\mathrm{n}$ \\
\hline 97.3 & 93,68 & 6,32 & $\mathrm{n}$ & $\mathrm{n}$ & $\mathrm{n}$ & $\mathrm{n}$ & $\mathrm{n}$ \\
\hline 98.5 & 83,59 & 16,41 & $\mathrm{n}$ & $\mathrm{n}$ & $\mathrm{n}$ & $\mathrm{n}$ & $\mathrm{n}$ \\
\hline 98.6 & 87,38 & 12,62 & $\mathrm{n}$ & $\mathrm{n}$ & $\mathrm{n}$ & $\mathrm{n}$ & $n$ \\
\hline 98.7 & 83,84 & 16,46 & $\mathrm{n}$ & $\mathrm{n}$ & $\mathrm{n}$ & $\mathrm{n}$ & $n$ \\
\hline 98.8 & 88,78 & 11,22 & $\mathrm{n}$ & $\mathrm{n}$ & $\mathrm{n}$ & $\mathrm{n}$ & $\mathrm{n}$ \\
\hline 98.13 & 91,66 & 8,34 & $\mathrm{n}$ & $\mathrm{n}$ & $\mathrm{n}$ & $\mathrm{n}$ & $\mathrm{n}$ \\
\hline 110.3 & 83,40 & 15,25 & $n$ & $\mathrm{n}$ & $\mathrm{n}$ & u & 0,88 \\
\hline 111.1 & 91,28 & 8,72 & $\mathrm{n}$ & $\mathrm{n}$ & $\mathrm{n}$ & $\mathrm{n}$ & $\mathrm{n}$ \\
\hline 111.2 & 90,89 & 9,11 & $\mathrm{n}$ & $\mathrm{n}$ & $\mathrm{n}$ & $\mathrm{n}$ & $\mathrm{n}$ \\
\hline 111.3 & 92,72 & 7,28 & $\mathrm{n}$ & $n$ & $\mathrm{n}$ & $\mathrm{n}$ & $n$ \\
\hline 111.4 & 80,18 & 19,92 & $\mathrm{n}$ & $\mathrm{n}$ & $\mathrm{n}$ & $\mathrm{n}$ & $\mathrm{n}$ \\
\hline 115.2 & 95,57 & 4,43 & $\mathrm{n}$ & $\mathrm{n}$ & $n$ & $\mathrm{n}$ & $n$ \\
\hline 115.3 & 92,63 & 7,37 & $n$ & $\mathrm{n}$ & $n$ & $\mathrm{n}$ & $\mathrm{n}$ \\
\hline 116.1 & 89,84 & 10,16 & $\mathrm{n}$ & $\mathrm{n}$ & $\mathrm{n}$ & $\mathrm{n}$ & $\mathrm{n}$ \\
\hline 116.2 & 94,31 & 5,69 & $\mathrm{n}$ & $\mathrm{n}$ & $\mathrm{n}$ & $\mathrm{n}$ & $\mathrm{n}$ \\
\hline 117.3 & 92,45 & 7,55 & $\mathrm{n}$ & $n$ & $\mathrm{n}$ & $n$ & $n$ \\
\hline 135.2 & 94,92 & 5,08 & $\mathrm{n}$ & $n$ & $\mathrm{n}$ & $\mathrm{n}$ & $\mathrm{n}$ \\
\hline 135.3 & 68,69 & 31,31 & $\mathrm{n}$ & $\mathrm{n}$ & $\mathrm{n}$ & $n$ & $n$ \\
\hline 148.2 & 87,73 & 8,42 & 3,85 & $n$ & $n$ & $n$ & $n$ \\
\hline 148.3 & 83,85 & 16,15 & $\mathrm{n}$ & $\mathrm{n}$ & $\mathrm{n}$ & $n$ & $\mathrm{n}$ \\
\hline
\end{tabular}

Tabla 5. Análisis metálicos de ajuares de la necrópolis de Peña Negra I, Crevillente, Alicante (Bronce final). 
cionadamente, desapareciendo cuando se sustituye por estaño. Una deficiencia de Laboratorio no puede esgrimirse ya que este lote se analizó conjuntamente con las muestras de Les Moreres y de Caramoro I, en donde el arsénico está presente. Nos quedaría barajar la posibilidad de que, dada la volatilidad de dicho elemento en la fusión, no hubieran quedado trazas del mismo.

El volumen de las actividades metalúrgicas realizadas en los talleres de Peña Negra fue de tal envergadura que ahora sí puede concederse a éstas el papel de factor determinante en la diferenciación social, entreviendo en el extenso poblado del Bronce Final la existencia de una jefatura política - que no negamos pudiera haberse dado con anterioridad en poblados del II milenio a.C. (Orihuela, Callosa, Villena) — que podría haber ostentado atributos de riqueza como los que adornaban al régulo que se vio obligado a ocultar su tesoro en la Rambla del Panadero de Villena, seguramente en una acción de paso.

Ese proceso hacia la jerarquización social, delatado desde el Calcolítico con la introducción de objetos de rango - marfil, metal, ítems religiosos, cerámica campaniforme-, alcanzará en el final de la Edad del Bronce su conclusión. De la presencia de estos regios personajes se hacen eco las posteriores fuentes escritas, válidas para las épocas orientalizante e ibérica.

Lógicamente, el control de estas actividades metalúrgicas, tanto de extracción como de producción, por sí solo no debió de constituir el detonante de dicha jerarquización - que bien pudo estar configurada en el Bronce Pleno-, pero en conjunción con un control de las vías de intercambio comercial, derivado de una capitalidad evidente sobre un amplio territorio, actuaría como factor coadyuvante en la eclosión de semejante proceso de diferenciación social, que no en vano adjetiva la época protohistórica.

Esta configuración socio-económica debió acelerarse aún más ante la presencia de gentes orientales que, atraídas por la producción metalúrgica indígena, habían comenzado a instalarse hacia el siglo VIII a.C. no sólo en el conjunto portuario de la desembocadura del río Segura (González Prats, 1990a y b, 1991 y 1992b; García Menarguez, 1995; González
Prats y García Menarguez, e.p.), sino incluso en el propio poblado de Peña Negra (González Prats, 1983a y 1986a), originando aquí un rápido despegue del núcleo urbano hacia lo que hemos de calificar con absoluta propiedad como una floreciente ciudad orientalizante, hasta tal punto que su nombre - Herna- llegó a ser registrado en las fuentes escritas prerromanas (González Prats, 1982, 1983a y f, 1992b, 1993a y b).

La dinámica social, cultural y económica que se instauró con estos contactos tuvo una última consecuencia en la producción metálica del último tramo del Bronce Final y en el Hierro Antiguo del Sudeste: la creación de un sistema monetal de intercambio a través de barras planas de metal cuya composición - cobres puros, bronces binarios y plomos- podría traducir los diversos valores que podían haberse conferido a tales piezas (González Prats, 1985b). La entidad de este sistema parece arrancar ya en el Bronce Final y se encuentra plenamente en vigor en el siglo VII a.C., en la etapa orientalizante. El hallazgo de una de estas piezas en el Arenero de La Fábrica, en la provincia de Madrid, no haría sino confirmar el flujo comercial que existe durante la primera mitad del I milenio a.C. entre la Meseta oriental y el Sudeste.

Con el siglo VII a.C. llegamos al momento en que en el ámbito indígena los utensilios de hierro comienzan a sustituir a las piezas de bronce, que quedarán relegadas al ámbito suntuario y religioso. Los hornos de Librilla (Ros Sala, 1989 y 1993) nos emplazarían ante los inicios de la actividad siderúrgica entre las poblaciones protohistóricas del Sudeste, cuyo desarrollo máximo lo llevarán a cabo los herreros ibéricos.

\section{BIBLIOGRAFÍA (2)}

Almagro Gorbea, M. (1978): "Problems of the origin of metallurgy in the Iberian Peninsula (Pre-Beaker metallurgy)". The Origins of Metallurgy in Atlantic Europe. Proceedings of the Fifth Atlantic Colloquium (Dublin, 1978) Ed. M. Ryan. Dublin: 1-6.

(2) En el listado bibliográfico se incluyen, además de los trabajos citados en el texto, las obras utilizadas para la confección de la Tablas 3a y b. 
Anguiz Pajarón, A. y Cremades, C. (1982): Del pasado ibense. Alcoy.

Aparicio Pérez, J.; Martínez, J.V.; Vives, E. y CAmpiLLO, D.(1981): Las Raíces de Bañeres (Alicante). Departamento de Historia Antigua. Serie Arqueológica, 8. Universidad de Valencia.

Arribas, A.; Craddock, P.; Molina, F.; Rothenberg, B. Y HoOKCK, D.R. (1989): "Investigación arqueo-metalúrgica en yacimientos de las Edades del Cobre y del Bronce en el Sudeste de Iberia". "Minería y Metalurgia en las antiguas civilizaciones mediterráneas y europeas". Ministerio de Cultura. Madrid: 71-79.

Ayala JuAn, M.M.; Polo, J.L. y ORTIZ, R.J. (1987): “Análisis por fluorescencia de rayos $\mathrm{X}$ de los útiles metálicos hallados en el enterramiento colectivo de La Salud, Lorca (Murcia)". Anales de Prehistoria y Arqueología, 3: 45-47.

- (1989): "Análisis por fluorescencia de rayos X de útiles metálicos de los yacimientos El Rincón de Almendricos (poblado en llanura) y el Cerro de las Viñas (poblado de altura)". XIX Congreso Nacional de Arqueología (Castellón, 1987): 293-307. Zaragoza.

BAllester Tormo, I. (1942): La labor del Servicio de Investigación Prehistórica y su Museo en los años 1935 a 1939. Servicio de Investigación Prehistórica. Diputación Provincial. Valencia.

- (1945): "Las recientes excavaciones del Servicio de Investigación Prehistórica". Archivo de Prehistoria Levantina, II: 349-367.

Belda Domínguez, J. (1930): Excavaciones en el Monte de la Barsella, término de Torremanzanas (Alicante). Memorias de la Junta Superior de Excavaciones y Antigüedades, 112. Madrid.

Bernabeu AubÁn, J. (1984): El Vaso Campaniforme en el País Valenciano. Trabajos Varios del S.I.P., 80. Valencia.

- (1986): "El Eneolítico valenciano: ¿horizonte Cultural o Cronológico?". El Eneolítico en el País Valenciano. Actas del Coloquio (Alcoy, 1984). Instituto de Estudios Juan Gil-Albert. Excma. Diputación Provincial: 914. Alicante.

Bernabeu Aubán, J.; Guitart, I. y Pascual, J.L. (1987): "El País Valenciano entre el final del Neolítico y la Edad del Bronce". El origen de la metalurgia en la Península Ibérica, II. Instituto Ortega y Gasset. Madrid, $1-15$.

BlANCE, B. (1959): "Estudio espectrográfico de algunos objetos metálicos del Museo de Prehistoria de Valencia”. Archivo de Prehistoria Levantina, VIII: 163-173.

- (1971): Die Anfünge der Metallurgie auf der Iberischen Halbinsel. S.A.M., 4. Berlin.

Boronat Soler, J.D. (1983): "Cova de les Maravelles (Jalón, Alicante)". Varia II: 43-77. Departamento de Historia Antigua. Valencia.

Borrego, M.; SAla, F. y Trelis, J. (1992): La Cova de la Barcella (Torremanzanas, Alicante). Catálogo de fondos del Museo Arqueológico, IV. Excma. Diputación Provincial de Alicante.

Botella Candela, E. (1926): Excavaciones en la Mola Alta de Serelles (Alcoy). Memorias de la Junta Superior de Excavaciones y Antigüedades, 79. Madrid.
Centre d'Estudis Contentans (1978): “La Mola d'Agres". Archivo de Prehistoria Levantina, XV: 99116.

CERdÁ Bordera, F. (1983): "Contribución al estudio arqueológico de la Foia de Castalla”. Lucentum, II: 69-90.

- (1994): "El II mil.lenni a la Foia de Castalla (Alacant). Excavacions arqueològiques a la Foia de la Perera (Castalla)". Recerques del Museu d'Alcoy, 3: 95-110.

Coffyn, A. (1985): "Le Bronze Final Atlantique dans la Peninsule Iberique". Diffusion de Boccard. Paris.

Colominas Roca, J. (1936): "La necrópoli de Las Laderas del Castillo, Callosa del Segura, prov. Alacant". Anuari de l'Institut d'Estudis Catalans, VIII: 33.

CORRAL CAÑón (1986): "Actividades comunitarias y privadas durante las edades del Metal. Un ejemplo: la metalurgia". Arqueología Espacial, 8: 219-233. Teruel.

- (1986): "Las primeras actividades metalúrgicas y su desarrollo en el País Valenciano". El Eneolítico en el País Valenciano. Actas del Coloquio (Alcoy, 1984), Instituto de Estudios Juan Gil-Albert. Excma. Diputación Provincial: 15-21. Alicante.

Cóurtin, J. (1974): Le Néolithique de la Provence. Mémoires de la Société Préhistorique Française, 11. Paris.

CuAdrado, E. (1950): "Útiles y armas de El Argar. Ensayo de tipología”. I Congreso Nacional de Arqueología (Almería, 1949): 103-125. Cartagena.

Chapman, R. (1991): "La formación de las sociedades complejas. El sureste de la Península ibérica en el marco del Mediterráneo occidental". Crítica. Barcelona.

ChARLES J.A. (1967): "Early Arsenical Bronzes: A metallurgical view". American Journal of Archaeology, 71: 21-26.

De Pedro Mrtxó, M.a. (1986): "Les coves d'enterrament eneolítiques: la Cova del Pic (Carcaixent, València)". El Eneolítico en el País Valenciano. Actas del Coloquio (Alcoy, 1984). Instituto de Estudios Juan Gil-Albert. Excma. Diputación Provincial: 65-72. Alicante.

Delibes De CASTRo, G. (1978): "Una inhumación triple de facies Cogotas I en San Román de la Hornija (Valladolid)". Trabajos de Prehistoria, 35: 225-250.

Delibes de Castro, G.; Fernández, J.; Martín Valls, R. Y Romero, F. (1985): La Prehistoria del Valle del Duero. "Historia de Castilla y León", I. Ámbito. Valladolid.

Delibes de Castro, G.; Fernández Miranda, M.; MARTín, A. y Molina, F. (1988): "El Calcolítico en la Península ibérica”. Congresso Internazionale L'Età del Rame in Europa. Rassegna di Archeologia, 7: 255-282.

Delibes de Castro, G.; Fernández Miranda, M.; FernÁndez-Posse, M.D.; Martín, C.; Rovira, S. Y SANZ, M. (1989): "Almizaraque (Almería): minería y metalurgia calcolíticas en el Sureste de la Península ibérica". "Minería y Metalurgia en las antiguas civilizaciones mediterráneas y europeas". Ministerio de Cultura. Madrid: 81-96.

Diz ARDid, E. (1982): $1 .^{a}$ Exposición de Arqueología de la Vega Baja. Excmo. Ayuntamiento. Orihuela.

T. P., 53, n. ${ }^{\circ} 1,1996$ 
Fernández Vega, A. (1984-85): "Cuevas de enterramiento de la Edad del Bronce en el País Valenciano". Cuadernos de Prehistoria y Arqueología U.A.M., 1112: $37-46$

Figueras Pacheco, F. (1934): Excavaciones en la Isla del Campello (Alicante), 1931-1933. Memorias de la Junta Superior de Excavaciones y Antigüedades, 132. Madrid.

- (1950): "La Isleta del Campello del litoral de Alicante. Un yacimiento síntesis de las antiguas culturas del Mediterráneo. Archivo Español de Arqueología, XXIII: 13-37.

Fletcher VAlls, D. y PlÁ, E. (1977): Cincuenta años de actividades del Servicio de Investigación Prehistórica (1927-1977). Trabajos Varios del SIP, 57. Valencia.

FurGús, J. (1909): "Necrópolis prehistórica de Orihuela (Necrópolis de la Sierra de Callosa del Segura)". Boletín de la Real Academia de la Historia, LIV: 335-368.

- (1937): Col.lecció de treballs del P. Furgús sobre prehistòria valenciana. Trabajos Varios del SIP, 5 . Valencia.

García Menarguez, A. (1995): "Avances sobre las excavaciones en yacimientos con fases del Hierro Antiguo en el tramo final del río Segura (Guardamar del Segura, Alicante)". XXII Congreso Nacional de Arqueología (Vigo, 1993): 225-229. Vigo.

García SÁNChez, M. y CARRASCO, J. (1979): “Análisis espectrográfico de objetos metalúrgicos de la provincia de Granada". XV Congreso Nacional de Arqueología (Lugo, 1977): 237-252. Zaragoza.

Gil Mascarell, M. (1983): "El poblado de la Edad del Bronce de la Mola d'Agres (Agres, Alicante)". XVI Congreso Nacional de Arqueología (Murcia, 1982): 276-286. Zaragoza.

Gil Mascarell, M. y PeÑa SÁnchez, J. L. (1994): "Las fases de ocupación en el yacimiento de la Mola d'Agres (Agres, Alicante): su dinámica evolutiva". Recerques del Museu d'Alcoy, 3: 111-120.

Gilman, A. (1976): "Bronze Age dynamics in southeast Spain". Dialectical Anthropology, 1: 307-319.

- (1987): "Unequal development in Copper Age Iberia". En E.M. Brumfiel y T.K. Earle (eds.): "Specialization, exchange and complex societies". Cambridge University Press. Cambridge; 22-29.

Gonçalves, V. Dos SANTOS (1989): Megalitismo e metalurgia no Alto Algarve oriental. Uma aproximaçâo integrada. Uniarq, Estudos e Memórias, 2. Lisboa.

GoNZÁlEZ PRATS, A. (1973): "Los enterramientos calcolíticos y de la Edad del Bronce del Mas de Felip (Ibi, Alicante)". Revista del Instituto de Estudios Alicantinos, 9: 47-51.

- (1982): "La Peña Negra IV. Excavaciones de 1980-81 en el Sector VII de la ciudad orientalizante". Noticiario Arqueológico Hispánico, 13, 309-418.

- (1983)a: Estudio arqueológico del poblamiento antiguo de la Sierra de Crevillente (Alicante). Anejo I de Lucentum. Universidad de Alicante. Alicante.

- (1983)b: "La necrópolis de cremación del Bronce Final de La Peña Negra de Crevillente (Alicante)". XVI Congreso Nacional de Arqueología (Murcia, 1982). Zaragoza: 285-294.
- (1983)c: "Peña Negra. Prehistoria y Protohistoria de la Sierra de Crevillente". Revista de Arqueología, 28: 6-15.

- (1985)a: "Los nuevos asentamientos del final de la Edad del Bronce: problemática cultural y cronológica". En Arqueología del País Valenciano: panorama y perspectivas (Elche, 1983), Universidad de Alicante. Alicante: $153-184$.

- (1985)b: "Sobre unos elementos materiales del comercio fenicio en tierras del Sudeste peninsular". Lucentum, IV: 97-106.

- (1986): "El poblado calcolítico de Les Moreres en la Sierra de Crevillente (Alicante)". El Eneolítico en el País Valenciano. Actas del Coloquio (Alcoy, 1984). Alicante: 89-99.

- (1989): "Últimas aportaciones de las excavaciones realizadas en La Peña Negra (1983-1987) al Bronce Final y Hierro Antiguo del Sudeste y País Valenciano". XIX Congreso Nacional de Arqueología (Castellón, 1987): 467-75. Zaragoza.

- (1990)a: Nueva luz sobre la protohistoria del Sudeste peninsular. Universidad de Alicante. Alicante.

- (1990)b: "La factoría fenicia de Guardamar". Azarbe, septiembre. Suplemento Cultural de la Revista de Fiestas. Ayuntamiento de Guardamar del Segura.

- (1991): "La presencia fenicia en el Levante peninsular y su influencia en las comunidades indígenas". I-IV Jornadas de Arqueología Fenicio-Púnica. Ibiza: 109-118.

- (1992)a: "Una vivienda metalúrgica en La Peña Negra (Crevillente-Alicante). Aportación al conocimiento del Bronce Atlántico en la Península Ibérica". Trabajos de Prehistoria, 49: 243-257.

- (1992)b: "El proceso de formación de los pueblos ibéricos en el Levante y Sudeste de la Península ibérica". Paletnología de la Península ibérica. Complutum, 2-3: 137-150.

- (1993)a: "Ausgrabungen in der Frühgeschichtlichen siedlung von Herna (La Peña Negra, Crevillente, prov. Alicante)". Madrider Mitteilungen, 34: 142-152.

- (1993)b: "Quince años de excavaciones en la ciudad protohistórica de Herna (La Peña Negra, Crevillente, Alicante)". Saguntum, 26: 181-188.

- (1993)c: "La metalurgia del Bronce Final en el Sudeste de la Península ibérica". "Metalurgia de la Península Ibérica durante el Primer milenio a.C. Estado actual de la investigación. Universidad de Murcia. Murcia: 21-43.

GonZÁlez Prats, A.; RuIZ, E.; GIL, F. y SEVA, R. (1995): "Cerámicas anatólicas en el poblado calcolítico de Les Moreres (Crevillente, Alicante, España)". I Congresso de Arqueologia Peninsular (Oporto, 1993). Actas V. Trabalhos de Antropologia e Etnologia, XXXV, 1: 131-141.

GonzÁlez Prats, A. y García MENARgueZ, A. (E.P.): "El conjunto fenicio de la desembocadura del río Segura (Guardamar del Segura, Alicante)". IV Congreso Internacional de Estudios Fenicios y Púnicos (Cádiz, 1995).

GonzÁlez Prats, A. y Ruiz-GÁlvez, M. (1989): "La metalurgia de Peña Negra en su contexto del Bronce Final del Occidente europeo". XIX Congreso Nacional de Arqueología (Castellón, 1987): 367-376. Zaragoza.

GonzÁlez Prats, A. y Ruiz Segura, E. (1990-91): "Nuevos datos sobre urbanística y cultura material en 
el Hierro Antiguo del Sudeste (Peña Negra, 1986)". Lucentum, IX-X: 51-75.

- (1994): "Nuevos datos sobre el poblado calcolítico de Les Moreres, Crevillente (Alicante). Campañas 19881993". Anales de Prehistoria y Arqueología de la Universidad de Murcia, 7-8: 17-20.

González Salas, S. (1945): El castro de Yecla, Santo Domingo de Silos (Burgos). Informes y Memorias, 7. Madrid.

GozÁlveZ-PÉrez, V. (1975): "Notas sobre el poblamiento antiguo en el término de Crevillente". Archivo de Prehistoria Levantina, XIV: 161-168.

GuILAINE, J. (1985): "Les débuts du Chalcolithic en Méditerranée occidentale". Varia II, 9-29. Departamento de Historia Antigua. Universidad de Valencia.

HARRISON, R.J. (1983): "Notas sobre el empleo de la plata en la cultura argárica del SE peninsular". Homenaje al Prof. Martín Almagro Basch, II, Ministerio de Cultura. Madrid: 17-21.

HARRISON, R.J. y CRADDOCK, P.T. (1981): “A Study of the Bronze Age Metalwork from the Iberian Peninsula in the British Museum". Ampurias, 43: 113-179.

Harrison, R.J.; Quero, S. y PrIEgo, M.C. (1975): "Beaker metallurgy in Spain". Antiquity, 49: 273-278.

Hernández Pérez, M.S. (1982): "Cueva de la Casa Colorá: un yacimiento eneolítico en el Valle medio del Vinalopó (Alicante)". Lucentum, I: 5-18.

- (1983): "La metalurgia prehistórica en el Valle Medio del Vinalopó (Alicante)". Lucentum, II: 1-42.

- (1985): "La Edad del Bronce en el País Valenciano: panorama y perspectivas". Arqueología del País Valenciano: panorama y perspectivas. Actas de las Jornadas (Elche, 1983). Universidad de Alicante. Alicante: 101-119.

- (1986): "La cultura de El Argar en Alicante. Relaciones temporales y espaciales con el mundo del Bronce Valenciano". Homenaje a Luis Siret (Cuevas de Almanzora, 1984). Consejería de Cultura de la Junta de Andalucía. Sevilla: $341-350$

- (1989): "Un enterramiento argárico en Alicante". Homenaje a Jerónimo Molina. Academia Alfonso X el Sabio. Murcia: 87-94.

- (1994): "La Horna (Aspe, Alicante). Un yacimiento de la Edad del Bronce en el Medio Vinalopó". Archivo de Prehistoria Levantina, XXI: 83-118.

Hernández Pérez, M.S.; Catala, E. y Ferrer, P. (1988): Arte Rupestre en Alicante. Fundación Banco Exterior. Banco de Alicante. Alicante.

Hernández Pérez, M.S. y Pérez Burgos, J.M. (1991): "Excavaciones en La Peña de Sax". Revista de Fiestas. Ayuntamiento de Sax. Sax: 28-31.

Hook, D.R.; Arribas, A.; Craddock, P.T.; Molina, F. y ROTHENBERGG, B. (1987): "Copper and silver in Bronze Age Spain". Bell Beakers of the western mediterranean. The Oxford International Conference. B.A.R., 331 (1). London: 147-172.

JiméneZ DE CISNERos, D. (1925): "Indicación de algunos yacimientos prehistóricos y noticias acerca de otros". Boletín de la Real Sociedad Española de Historia Natural, XXV: 71-81.

Jover Maestre, F.J. y Segura Herrero, G. (1992-93): "El asentamiento del Portixol (Monforte del Cid, Ali- cante). Contribución al estudio del Bronce Tardío del río Vinalopó". Alebus, 2-3: 25-58.

JuAn CABANilles, J. (1990): “A propòsit d'un punyal de retoc en peladures i sílex polit de la Cova del Barranc de l'Infern (Gandía, València)". Archivo de Prehistoria Levantina, XX: 201-222.

Lerma Alegría, J.V. (1981): "Los orígenes de la metalurgia en el País Valenciano". Archivo de Prehistoria Levantina, XVI: 129-140.

López Mira, J.A. y Ortega PÉrez, J.R. (1991): Historia de Novelda. La Prehistoria, 2. Excmo. Ayuntamiento. Novelda.

LÓPEZ SEGUí, E. (1990): "Contribución al estudio arqueológico de Agost (Alicante)". Actas del Congreso de Jóvenes Historiadores y Geógrafos. Madrid.

LóPez Segui, E.; García, M.A. y Ortega, J.R. (1992): "La Cueva del Cantal (Biar, Alicante)". Lucentum, IX$\mathrm{X}: 25-50$

Lull, V. (1983): “La cultura de El Argar. Un modelo para el estudio de las formaciones económico-sociales prehistóricas". Akal. Madrid.

Lull, V. y EstéVEZ, J. (1986): "Propuesta metodológica para el estudio de las necróplis argáricas". Homenaje a Luis Siret (Cuevas de Almanzora, 1984). Consejería de Cultura de la Junta de Andalucía. Sevilla: 441-452.

Llobregat Conesa, E.A. (1971): "Eine Siedlung des Bronce Valenciano auf Serra Grossa (Alicante)". Madrider Mitteilungen, 12: 96-100.

- (1969): "El poblado de la cultura del Bronce Valenciano de la Serra Grossa, Alicante". Papeles del Laboratorio de Arqueología de Valencia, 6: 31-75.

- (1975): "Nuevos enfoques para el estudio del período del Neolítico al Hierro en la Región Valenciana". Papeles del Laboratorio de Arqueología de Valencia, 11: 119-140.

- (1979): "Iniciación a la Arqueología Alicantina". Caja de Ahorros Provincial. Alicante.

MArtí Oliver, B. (1983): "La Muntanya Assolada (Alzira, Valencia)". Lucentum, II: 43-67.

Martín, C.; Fernández-Miranda, M.; FernándezPosse, M.D. y Gilman, A. (1993): "The Bronze Age of La Mancha". Antiquity, 67 (254): 23-45.

Martín Socas, D. y CAMALICH, M.D. (1986): "Las excavaciones en el poblado de Campos (Cuevas de Almanzora, Almería) y su problemática". Homenaje a Luis Siret (Cuevas de Almanzora, 1984). Consejería de Cultura de la Junta de Andalucía. Sevilla: 171-191.

Martín Valls, R. y Delibes, G. (1989): La cultura del vaso campaniforme en las campiñas meridionales del Duero. El enterramiento de Fuente Olmedo (Valladolid). $2^{\text {a }}$ edición aumentada. Monografías del Museo Arqueológico de Valladolid, 1. Valladolid.

MellinK, F.J. (1993): "The Anatolian South Coast in the Early Bronze Age". Between the Rivers and over the Mountains. Roma: 495-508.

MoHEN, J.P. (1973): "Les moules en terre cuite des bronziers protohistoriques". Antiquités Nationales, 5: 35-41.

- (1984): "Nouvelles découvertes de vestiges métallurgiques de l'Âge du Bronze à Fort-Harrouard, Sorel Moussel (Eure et Loire)". Paléometallurgie de la France Atlantique. Âge du Bronze, 1. Rennes.

T. P., 53, n. ${ }^{\circ} 1,1996$ 
- (1984-85): "Les outils des métallurgistes de l'Age du Bronze en France". Antiquités Nationales, 16/17: 89-96.

MoHen, J.P. y BAILloud, G. (1987): La vie quotidienne. Les fouilles de Fort-Harrouard. L'Âge du Bronze en France, 4. Picard. Paris.

Molina GonZÁlEZ, F. (1978): “Ensayo de sistematización y periodización del Bronce Tardío y Final en el Sudeste de la Península ibérica". Cuadernos de Prehistoria de Granada, 3: 159-232.

Monteagudo, L. (1977): Die Beile auf der iberischen Halbinsel. Prähistorische Bronzefunde. Munich.

MonTERo Ruiz, I. (1990): "Minería prehistórica del cobre: planteamientos de investigación". Cuadernos del Suroeste, 1: 7-10.

- (1992): "La actividad metalúrgica en la Edad del Bronce del Sudeste de la península ibérica: tecnología e interpretación cultural". Trabajos de Prehistoria, 49: 189-215.

- (1993): "Bronze Age metallurgy in southeast Spain". Antiquity, 67 (254): 46-57.

- (1994): El origen de la metalurgia en el Sudeste peninsular. Instituto de Estudios Almerienses. Colección Investigación. Serie Historia, 19. Almería.

NAVARro MEderos, J.F. (1982): "Materiales para el estudio de la Edad el Bronce en el valle medio del Vinalopó (Alicante)". Lucentum, I: 19-70.

- (1983): "La explotación del territorio de la Península ibérica durante el Bronce Pleno. Aproximación a su estudio". Tabona, IV: 29-93.

PASCUAl Benito, J.L. (1988): "Les coves sepulcrals de l'Alberri (Cocentaina). El poblament de la Vall Mitjana del riu d'Alcoi durant el III mil.leni a.C." Saguntum, 21: 109-167.

- (1990): "L'Edat del Bronce en la comarca del Comtat". Ayudas a la Investigación 1986-1986, III: 83-103. Instituto de Estudios Juan Gil-Albert. Alicante.

Pascual PÉrez, V. (1963): "Hallazgos prehistóricos en Les Llometes (Alcoy)". Archivo de Prehistoria Levantina, X: 39-59.

- (1969): "Un nuevo enterramiento del Bronce Valenciano en el Mas de Felip de Ibi". Papeles del Laboratorio de Arqueología de Valencia, 6: 71-75.

PlÁ BAllester, E. (1947): El Sercat de Gayanes (Alicante). Trabajos Varios del SIP, 10. Valencia.

PONSEll CORTÉs, F. (1926): Excavaciones en la finca Mas de Menente, término de Alcoy (Alicante). Memorias de la Junta Superior de Excavaciones y Antigüedades, 78. Madrid.

Poveda Navarro, A. (1988): "El poblado ibero-romano de El Monastil (Elda, Alicante). Introducción Histórico-Arqueológica”. Excmo. Ayuntamiento de Elda y Universidad de Alicante. Elda.

RAmos Folqués, A. (1989): "El Eneolítico y la Edad del Bronce en la comarca de Elche". Ayuntamiento de Elche. Elche.

Rodríguez Vinceiro, F.J.; FernÁndez, L.E.; Clavero, J.L.; Romero, J.C.; Von Thode, C.; García, A.; SuÁreZ, J.; Barrera, M. y Palomo, A. (1992): "Estado actual de la investigación arqueometalúrgica prehistórica en la provincia de Málaga". Trabajos de Prehistoria, 49: 217-242.
Ronda Femenia, A. (1990): "Arqueología de Benissa". Excmo. Ayuntamiento de Benissa. Instituto de Cultura Juan Gil-Albert. Alicante.

Ros DUEÑAs, A. (1980): "El poblado prehistórico de El Bancalico de los Moros y El Rincón (Redován, Alicante)". Revista del Instituto de Estudios Alicantinos, 30: 7-43.

Rosa SAla, M.M. (1980): "El Bronce Final: los orígenes del mundo ibérico". "Historia de la Región de Murcia", II. Ed. Mediterráneo. Murcia: 103-117.

- (1989): "Dinámica urbanística y cultura material del Hierro Antiguo en el valle del Guadalentín". Colegio Oficial de Arquitectos. Universidad de Murcia.

- (1993): "El trabajo del hierro en el poblado protohistórico de El Castellar (Murcia), I: Análisis arqueológico". "Metalurgia en la Península Ibérica durante el primer milenio a.C. Estado actual de la investigación". Universidad de Murcia. Murcia: 71-109.

Rothenberg, B.; García, F.; CACHMANN, H.G. y GoetHE, J.W. (1989): "The Río Tinto enigma". "Minería y Metalurgia en las antiguas civilizaciones mediterráneas y europeas". Ministerio de Cultura. Madrid: 57-70.

RoviRA, S. (1989): "Estudio arqueometalúrgico de una fíbula «ad occhio» de la Mola d'Agres (Alicante)". Saguntum, 22: 143-144.

- (1989): "Recientes aportaciones para el conocimiento de la metalurgia primitiva en la provincia de Madrid: un yacimiento campaniforme en Perales del Río (Getafe, Madrid)". XIX Congreso Nacional de Arqueología (Castellón, 1987). Zaragoza: 355-366.

Rovira, S.; Martínez, C.; Botella, M.C. y SANZ, M.S. (1984): “Análisis metalográfico de las piezas de bronce procedentes del Peñón de la Reina (Alboloduy, Almería)". Primeras Jornadas de Metodología de Investigación Prehistórica (Soria, 1981). Ministerio de Cultura. Madrid: 341-358.

Rovira, S.; Montero, I. y Consuegras, S. (1992): "La metalurgia de la Edad del Bronce en la provincia de Soria". Actas del II Symposium de Arqueología Soriana. Excma. Diputación Provincial de Soria. Soria: 247-259.

RovirA, S. Y MONTERO, I. (1994): "Metalurgia campaniforme y de la Edad del Bronce en la Comunidad de Madrid". En C. Blasco (ed.): "El Horizonte Campaniforme de la región de Madrid en el Centenario de Ciempozuelos". Universidad Autónoma de Madrid. Madrid: 137-171.

Rovira, S. y SANZ, M. (1983): "Estudio arqueometalúrgico de las piezas metálicas de El Peñón de la Reina (Alboloduy, Almería)". Antropología y Paleoecología Humana, 3: 193-202.

Rubio Gomis, F. (1987): Catálogo de materiales y yacimientos de la Cultura del Bronce Valenciano, I: L'Ull del Moro. Excmo. Ayuntamiento. Alcoy.

Ruiz GÁlvez, M. (1979): "El Bronce Antiguo en la fachada atlántica peninsular: un ensayo de periodización". Trabajos de Prehistoria, 36: 151-172.

- (1986): "Navegación y comercio entre el Atlántico y el Mediterráneo a fines de la Edad del Bronce”. Trabajos de Prehistoria, 43: 9-42.

SANGMEISTER, E. (1960): "Metalurgía y comercio del cobre en la Europa prehistórica”. Zephyrus, XI: 131-139.

T. P., 53, n. ${ }^{\circ} 1,1996$ 
SAN NiCOLÁs, M. (1988): "Objetos metálicos eneolíticos y argáricos en Murcia”. Anales de Prehistoria y Arqueología, 4: 71-78.

SCHUbART, H. (1973): "Las alabardas tipo Montejícar". Estudios dedicados al Dr. Luis Pericot. Publicaciones Eventuales, 23. Barcelona: 247-269.

Segura Martí, J.M. (1985): "Aproximación al estudio de la Prehistoria y Antigüedad en la Valleta d'Agres". Miscelánea histórica de Agres. Excmo. Ayuntamiento de Agres. Alcoy: 39-45.

SimÓN GARCÍA, J.L. (1988): "Colecciones de la Edad del Bronce en el Museo Arqueológico Provincial de Alicante. Ingresos de 1967 a 1985 e Illeta dels Banyets de El Campello". Ayudas a la Investigación 1984-1985, II: 111134. Instituto de Estudios Juan Gil-Albert. Alicante.

- (1988): "Xàbia a la Edat del Bronce". Xábiga, 3: 7-36

- (1990): "Catálogo y estudio de los fondos prehistóricos (del V al II milenio) de los Museos de la Marina Alta". Ayudas a la Investigación 1986-1987. Instituto de Estudios Juan Gil-Albert. Alicante: 105-122.

- (1995, inédito): La metalurgia prehistórica en el País Valenciano. Tesis doctoral inédita. Universidad de Alicante.

SIRET, E. Y L. (1890): "Las primeras edades del metal en el Sudeste de España”. Barcelona.

SOler García, J.M. a (1981): El Eneolítico en Villena. Departamento de Historia Antigua. Serie Arqueológica, 7. Universidad de Valencia.

- (1961): "La Casa de Lara en Villena (Alicante). Poblado de llanura con cerámica cardial". Saitabi, XI: 193-200.

- (1965): El Tesoro de Villena. Excavaciones Arqueológicas en España, 36. Madrid.

- (1983): "La Cueva del Molinico (Villena, Alicante)". El Eneolítico en el País Valenciano. Actas del Coloquio (Alcoy, 1984). Instituto de Estudios Juan Gil-Albert. Alicante: 111-118.

- (1986): "La Edad del Bronce en la comarca de Villena". Homenaje a Luis Siret (Cuevas de Almanzora, 1984). Consejería de Cultura de la Junta de Andalucía: 381424. Sevilla.

- (1987): "Excavaciones Arqueológicas en el Cabezo Redondo (Villena, Alicante)". Instituto de Estudios Juan Gil-Albert. Alicante.
SOlER García, J.M. ${ }^{a}$ y FernÁNDEZ-Moscoso, E. (1970): "Terlinques. Poblado de la Edad del Bronce en Villena (Alicante)". Papeles del Laboratorio de Arqueología de Valencia, 10: 27-62.

SORIANO SÁnCHEZ, R. (1984): "La cultura del Argar en la Vega Baja del Segura". Saguntum, 18: 103-143.

- (1985): "Contribución al estudio del Bronce Tardío y Final en la Vega Baja del Segura”. Saguntum, 19: 107-129.

- (1986): "Notas sobre el Eneolítico y los orígenes del poblamiento de la Edad del Bronce en la Vega Baja del Segura". El Eneolítico en el País Valenciano. Actas del Coloquio (Alcoy, 1984). Instituto de Estudios Juan Gil-Albert. Alicante: 139-143.

TARAMELli, A. (1921): "Il ripostiglio dei bronzi nuragici di Monte Sa Idda di Decimoputzu (Cagliari)". Monumenti Antichi, XXVII: 7-78.

Trellis Martí, J. (1984): "El poblado de la Edad del Bronce de la Mola Alta de Serelles (Alcoy, Alicante)". Lucentum, III: 23-66.

- (1988): "Mas del Corral". Memòries de la Consellería de Cultura, Educació i Ciència, 1984-1985. Generalitat Valenciana. Valencia: 82-85.

- (1992): "Excavaciones en el yacimiento de la Edad del Bronce de Mas del Corral (Alcoy-Alicante)". Recerques del Museu d'Alcoy, 1: 85-89.

Trellis Martí, J. y Vicens Petit, J.M. (1986): "El Eneolítico en Alcoy. Bases para su estudio". El Eneolítico en el País Valenciano. Actas del Coloquio (Alcoy, 1984). Instituto de Estudios Juan Gil-Albert. Alicante: 101-110.

Vicedo Sanfelipe, R. (1920-22): "Historia de Alcoy y su Región". Alcoy.

Vicens Petit, J.M. (1984): "Eneolítico". Alcoy, Prehistoria y Arqueología. Cien años de investigación. Excmo. Ayuntamiento de Alcoy. Instituto de Estudios Juan Gil-Albert. Alicante: 175-193.

Visedo Moltó, C. (1959): Alcoy, Geología, Prehistoria. Publicaciones del Instituto Alcoyano de Cultura Andrés Sempere, V. Alcoy.

WALKER, M.J. (1981): "El yacimiento prehistórico de Catí Foradá, Petrel, Alicante". Revista del Instituto de Estudios Alicantinos, 32: 87-89.

T. P., 53, n. ${ }^{\circ} 1,1996$ 